Int. J. Electrochem. Sci., 12 (2017) 10140 - 10151

\title{
Preparation and Characterization of Polyaniline / Glassy Carbon Modified Electrode as an Electrocatalyst for the Production of $\mathrm{Hydrogen}$ from $\mathrm{Et}_{3} \mathrm{NHCl} /\left[\mathrm{Bu}_{4} \mathrm{~N}\right]\left[\mathrm{BF}_{4}\right]-\mathrm{CH}_{3} \mathrm{CN}$ Solution
}

\author{
M. M. El-Deeb ${ }^{1,2^{*}}$, K. Alenezi ${ }^{1}$, H. El Moll ${ }^{1}$, M. El-Masry ${ }^{1,3}$ and Z. Matarneh $^{1}$ \\ ${ }^{1}$ Chemistry Department, Faculty of Science, Ha'il University, 81451 Hail, P.O. Box 2440, KSA \\ ${ }^{2}$ Chemistry Department, Faculty of Science, Beni-Suef University, 62514 Beni-Suef, Egypt \\ ${ }^{3}$ Polymer Materials Research Department, Advanced Technology, and New Materials Research Institute, \\ SRTA-City, New Borg El-Arab City 21934, Alexandria, Egypt \\ *E-mail: eldeebm@yahoo.com
}

doi: $10.20964 / 2017.11 .71$

Received: 9 July 2017 / Accepted: 12 September 2017 / Published: 12 October 2017

Crystalline, porous and fibril-like structure polyaniline film is electrodeposited on glassy carbon electrode from acidic solution. The electrochemical behaviour of polyaniline/glassy carbon modified electrode in $\left[\mathrm{Bu}_{4} \mathrm{~N}\right]\left[\mathrm{BF}_{4}\right]-\mathrm{CH}_{3} \mathrm{CN}$ solution is investigated using cyclic voltammetry technique. It shows a stable electroactive region which is related to the semiconducting state of polyaniline in nonaqueous medium. The electro-catalytic performance of the modified electrode toward Hydrogen Evolution Reaction $(H E R)$ from $\mathrm{Et}_{3} \mathrm{NHCl} /\left[\mathrm{Bu}_{4} \mathrm{~N}\right]\left[\mathrm{BF}_{4}\right]-\mathrm{CH}_{3} \mathrm{CN}$ solution shows a positive shift in the direct proton reduction potential as well as a higher catalytic reduction current density compared to the unmodified electrode with a good stability of $73.7 \%$ current retention after 25 repetitive cycles. The electrocatalytic activity of the modified electrode is correlated to its morphology.

Keywords: polyaniline, Hydrogen Evolution Reaction, electrocatalysis, cyclic voltammetry, surface characterization

\section{FULL TEXT}

(C) 2017 The Authors. Published by ESG (www.electrochemsci.org). This article is an open access article distributed under the terms and conditions of the Creative Commons Attribution license (http://creativecommons.org/licenses/by/4.0/). 